\title{
Assessing Psychological Effects of Cyberbullying on the Adolescents of a Cosmopolitan City
}

\author{
Dr Shovan Ghosh ${ }^{\dagger}$ and Sucharita Pramanick ${ }^{*^{*}}$
}

\section{Abstract}

The popularity of computer-mediated communication and cyber technology has created many new vices in society that obstruct the development of adolescents. One such vice is cyberbullying, which is an insidious and covert form of bullying. The present paper opts to scrutinise cyberbullying's psychological effects on the victim teenagers of minority communities of a cosmopolitan city. Confirmatory factor analysis, for testing the Psychological Effect of Cyberbullying Scale (PECS) comprising 24 direct item pool, was employed to unfold Mild Psychological Effect Scale (MPES) and Intense Psychological Effect Scale (IPES). Cross validating the initial factor structure was conducted with the help of developing standardised coefficient for the two factor model for PECS. Cronbach's alpha reliability coefficient values are above 0.09 for the items of both the Mild Psychological Effect Scale (MPES) and Intense Psychological Effect Scale (IPES). Based on purposive sampling, the study found that all the items taken for conducting the survey are highly co-related to the psychological impact of the victim teens of the minority community of the cosmopolitan city. So the PECS developed for measuring the effect has significance. Study results also indicate that the PECS can serve as a valuable tool for measuring the mental impact of cyberbullying among teenagers.

Keywords: Cyberbullying; Minority Community; Psychological Effect; Cosmopolitan; Teenager; Kolkata Municipal Corporation; India

\footnotetext{
+ Associate Professor, Department of Geography, Diamond Harbour Women's University, Diamond Harbour Road, Sarisha, District: South 24 Pargana, West Bengal, India, Pin: 743368 Email: ghoshshovan80@rediffmail.com

¥ Assistant Professor, Department of Geography, Rabindra Mahavidyalaya, Champadanga,

District: Hooghly, West Bengal, India, Pin, 71240, Email id: sucharitapramanick21@gmail.com

${ }^{*}$ Corresponding Author, Email id: sucharitapramanick21@gmail.com

(C) 2021 Ghosh \& Pramanick. This is an Open Access article distributed under the terms of the Creative Commons Attribution License (http://creativecommons.org/licenses/by/2.0), which permits unrestricted use, distribution, and reproduction in any medium, provided the original work is properly cited.
} 


\section{Introduction}

In the last few decades, the internet has provided an easy opening into the outside world. The exponential advancement in the field of technology has immensely changed the way people communicate and interact. Children and teenagers are also getting exposed to this virtual world at an early stage of their life. Their early exposure with little security knowledge is making them leisurely devour of cyber technology. They have the knowledge and skill to manipulate this technology. However, they often lack the judgement of what is right and what is wrong. This can mislead them to the opposing sides of the cyber world. Teenagers sometimes use this technology to oppress or harm others (Usher, 2010). One such effect is cyberbullying (Guidance Report of Welsh Government, 2011), which the adolescents use to hurt peers (Burton, 2014).

It is difficult to get a universally applicable definition of cyberbullying. Cyberbullying is:

when a child, preteen, teen is tormented, threatened, harassed, humiliated, embarrassed or otherwise targeted by another child, preteen or teen using internet, interactive or digital technologies, or mobile phones. It has to have minors on both sided, or at least have been instigated by a minor against another minor (Aftab, 2000; Marczak \& Coyne, 2015, pp. 147).

So both the bully and the victim have to be minor to call it 'cyberbullying' (Burton, 2014).

Adolescents' social development is influenced by hormonal changes along with social influences (Boyd, 2000). During this stage of life, the conditions are favourable for bullying, as most adolescents are confused and start getting exposed to the outer world. In cyberspace, they are on a virtual island with no adult supervision and very few rules. These cause the escalation in the chances of cyberbullying incidents, even to life-threatening levels (Shariff \& Hoff, 2007). Adolescents involved in cyberbullying can be categorised into three distinct groups: bullies, bully-victim and victims. While bullies engage in aggressive behaviour to achieve certain goals, victims are the ones subjected to harassment of bullies. Bully-victims who retaliate or later themselves get engaged in bullying others (Aricak et al., 2008).

Harassment on cyberspace can take a variety of forms, including threatening, sexual messages and obscene messages delivered via email, instant messaging services, or posts in chatrooms. Cyberstalkers can also impersonate their victims online by stealing personal information like logging information for an email account or social networking page (Marcum et al., 2014). Cyberspace provides adolescents with the ability to withhold their identity, providing them with a unique method to assert their dominance (Guidance Report of Welsh Government, 2011; Ybarra \& Mitchell, 2004). The limited capacity of self-regulation and susceptibility to peer pressure turn adolescents more at risk of cyberbullying (Horowitz \& Bollinger, 2014).

Incidence of cyberbullying increases and threatens the growing years of the adolescent population (Lee et al., 2017). Sometimes it can be even more harmful than traditional bullying because its features and characters like escaping are problematic and hurtful or embarrassing pictures, videos can be shared among innumerable people. In some instances, it becomes the tool of revenge and rage. Most of the time, adolescents do not have the mental strength of not considering and avoiding the acts of the bully. It let down their juvenile spirits and lowers their self-esteem and self-confidence (Price \& Dalgleish, 2010). They feel sad, hopeless and bad about themselves. This feeling of frustration is often transformed into anger and rage (Beran \& Li, 2005).

Since the bully is anonymous in many cases, the victim even finds it difficult to trust friends and family. They start avoiding friends and activities. Soon they also lose the urge to socialise (Best et al., 2014). This social isolation makes them feel lonely. They even become hopeless about their future life. All these passive psychological effects 
retard their healthy mental development. This harassment affects their mind, and they find it difficult to concentrate on their studies. They do not like going to school. It leads to long absence in school and lower examination grades (Brown et al., 2006). They often experience stressrelated health problems, like headache, stomach ache, apathy for food, nausea, vertigo etc. Sometimes, online bullying's psychological effect is so intense that adolescents can even think of harming or hurting themselves and others. The sense of no escape, force them to contemplate and even attempt suicide. Innumerable cases of cyberbullying related to suicides have been noted as well as recorded throughout the world (High,2007). It also paves the way for them to become delinquent juveniles and criminal adults in future.

These malefic psychological effects of cyberbullying on teenagers are of serious concern for society. However, the teenagers' physical, social reality and cyber social reality vary, depending on their socio-cultural environment. A cosmopolitan city often inhabits a culturally pluralistic society, which adds new challenges to teenagers' growing up. They have to develop the capability of cultural integration. Integration refers to a bicultural model of acculturation, in which individuals maintains their cultural heritage while participating actively in the larger society. It helps individuals function effectively in different environments (Greenfield \& Cocking, 2014). This process becomes an important tool, especially for the minority community, to adjust and adapt to the majority community dominated culture of a cosmopolitan city. So the nature and dynamics of cyberbullying and its effects can be more complicated for the teenagers of minority communities of these urban areas. Against these backdrops, this present research opts to scrutinise cyberbullying's psychological effects on the adolescents of minority communities residing in Ekbalpur, Mominpur, Park Circus and Raja Bazar areas of Kolkata Municipal Corporation, India.

Society of developing countries exhibits a quasideveloped structure, which is more prominent in its urban areas. India is one of the leading developing countries in the world. Its large cosmopolitan cities like Delhi, Mumbai, Kolkata and others have both the challenges of the under-developed ones and the potential opportunities of the developed ones. Kolkata is the largest metropolitan city in eastern India. As outlined above, this study intended to investigate online bullying in the urban areas of Kolkata Municipal Corporation, which is considered among India's topmost cities. The exposure to global culture acted as a catalyst in forming a cosmopolitan society, whereas the long history of migration leads to the growth of a culturally heterogeneous pluralistic society.

Moreover, like children of any other cities of India and elsewhere, the young generations in Kolkata too get used to modern technology, media and the cyber world from early childhood. The socio-economic environment is favourable for ample use of the internet and having profiles on social networking sites at a very early stage in life is one of the first markers. In addition to this, the mushrooming of the flat-apartment culture, breaking of traditional joint family structure, single parenting, and the adults' timedemanding work schedule has led to the increasing dependence of children on virtual relations. This is a perfect set-up for accelerating the problem cyberbullying and tracing the prominent psychological impact of cyberbullying on teenagers. According to the National Crime Record Bureau of India report, there are 88 cases of cyber-crimes against children in India in 2017. Among them, 29 cases have been found in metropolitan cities, and Kolkata alone has recorded 18 of such cases $(22.78 \%$ of the total cases in India), making it the first ranking city in this respect.

Most of the previous researches had focused on the examination of the factors that are involved in cyberbullying. Studies had also attempted to discourse the role of the people involved, like the bully, victim and the bystanders. Many had focused on the response aspect of the cyberbullying. The present study tries to highlight the psychological effects of cyberbullying on victim teens. There is a lack of 
detailed study on this domain of cyberbullying so far. The study area of this paper is a cosmopolitan city which has complex cultural structure. It gave a unique dimension to the study. The study's purpose was to reveal the general and commonly found psychological impacts of cyberbullying on the victim teens.

Further, the impacts were categorised based on the intensity with which the victims experienced them. The research also tried to form a general model of these psychological impacts of online bullying on the victim teens with the help of the statistical data and its analysis. It attempted to improve the knowledge and understanding of the victim teens' psychological aspects, emotional experiences, and behaviour pattern. It can enhance the effectiveness of the response offered to them by the bystanders and society. The study also tried to emphasise the reactions and behaviour of the victims of the minority community.

The research could be broadly divided into two parts. The first part consists of identifying the various psychological impacts and the collection of sample for the study. The second part includes analysing the data extracting the factors and building a model based on it. In the data analysis part, the first section deals with confirmatory factor analysis which indicates the grouping of variables into two critical factors. The second section of the data analysis part includes the development of a two factor model of psychological impacts, based on the results and finding of the confirmatory factor analysis. To test the reliability of the model, Cronbach alpha test had been conducted before the formation of the model.

\section{Methods and Materials}

\section{Study Site}

Kolkata $\left(22^{\circ} 30^{\prime}\right.$ North latitude, $88^{\circ} 30^{\prime}$ East longitude), the capital of West Bengal state of India, is the largest metropolitan city of the East and North Eastern India. Situated on the eastern bank of river Hooghly, it was the capital of the British Empire in India till 1911. The partition of
Bengal in 1947 caused a massive Hindu migration from East Bengal, presently Bangladesh to Kolkata. At present, in Kolkata, the Bengali Hindus form the majority. There are a large number of Hindu migrants from neighbouring states which include Hindi speaking Marwaris, Biharis along with Tamils and Odias. Besides, there is a relatively substantial presence of Anglo-Indians, Chinese, Goans, Syrians, Christians, Parsis and Jews along with a sizeable Muslim community. According to the District Statistical Handbook, Kolkata (2013), the religious composition of Kolkata is heterogeneous - $80.60 \%$ of the population is Hindu, $17.72 \%$ of the population is Muslims, $0.87 \%$ of the population is Christians, and $0.36 \%$ of the population is Sikh. The remaining $0.46 \%$ is composed of Jains, Buddhists and other religions.

Kolkata is often referred to as the 'cultural capital of India' (Engfer, 2003). Sometimes instead of converting the city into a melting pot of culture, the migrants maintain their exclusiveness and give rise to multicultural cities. Kolkata is an excellent example of it. The various migrated communities have contributed to developing a complex, yet a diverse and enriched culture of Kolkata. They have created distinct residential concentrations. The city can be divided spatially into different zones based on its socio-cultural mosaic like the regions of affluent high-class residential areas of Alipore, New Alipore, Ballygaunge; the highly knowledgeable service oriented middle-class areas of Behala, Tollygaunge, Shayambazar; the minority areas of Ekbalpur, Mominpur, Park Circus, Tangra and the areas with migrants from other states like Posta, Bara Bazar. Since the Muslims constitute the maximum number among the minority community, the survey was carried out mainly in the Muslim dominated areas. The main city of Kolkata is under Kolkata Municipal Corporation(KMC) which has an area of 184 sq. km. KMC comprises 16 boroughs, which together encompass 144 wards (Figure I). Out of these 2,3,4,6,7,9,15 are Muslim minority dominated boroughs. 


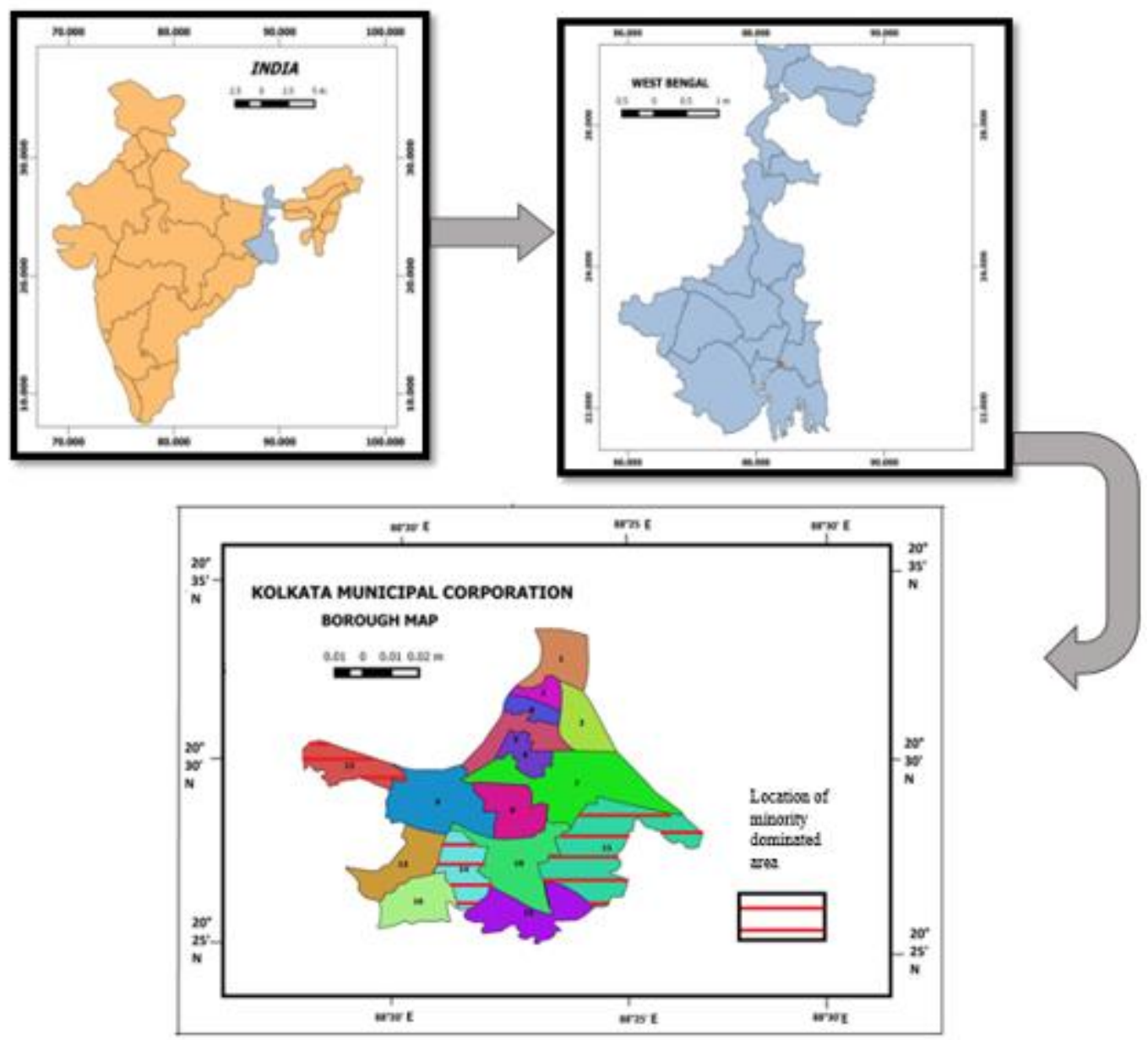

Figure 1: Location of the Study Area Demarcating the Muslim Minority Dominated Boroughs of Kolkata Municipal Corporation

Source: Recreated by the Authors from Maps obtained from Kolkata Municipal Corporation

\section{Sample}

Two different samples were used to develop the parameters of intense and mild psychological effects of cyberbullying on the teenagers of the minority communities of the cosmopolitan city. The first sample was used for validating the item pools and pilot survey as well, while the second one was used for the central survey of confirmatory factor analysis (CFA).

The pilot survey sample consisted of 40 teenagers ( 23 females and 17 males) from the minority-dominated areas like Ekbalpur and Park Circus areas of the city. The second sample of the main study consisted of 174 teenagers (95 females and 79 males) from Mominpur, Ekbalpur, Park Circus and Rajabazar areas of
Kolkata, which are the main residing places of the minorities. The samples were surveyed based on the validation and revised questionnaire built from the first sample pilot survey responses.

Students from grade nine to twelve were mainly surveyed. Students of grades below nine were not surveyed during the pilot survey as it became evident that below this grade using the internet for communication and having email id or profiles on social networking is very rare. Hence, the adolescents' selection was based on their age and students between the age of 14 years to 19 years were allowed to participate in the study. 


\section{Instrument}

The steps involved (Figure 2) in the study is as follows:

\section{Step 1: Literature Review and development of the item pool}

The first step was an exhaustive literature review of cyberbullying and its effects, especially teenagers' psychological effects. Studies related to socio-economic conditions of the minority communities of the study area was also conducted (Chaudhuri, 1990; Biswas, 2015). The extensive literature survey of the different journal articles, books and thesis based on the psychological effects of cyberbullying helped to list the items related to psychological and other associated reactions and behaviours of the victim teens (Beran \& Li, 2005; Brown et al., 2006; Price \& Dalgleish, 2010). The review of the already existing literature was used to develop the questionnaire. It also helped in its improvement by content validity.

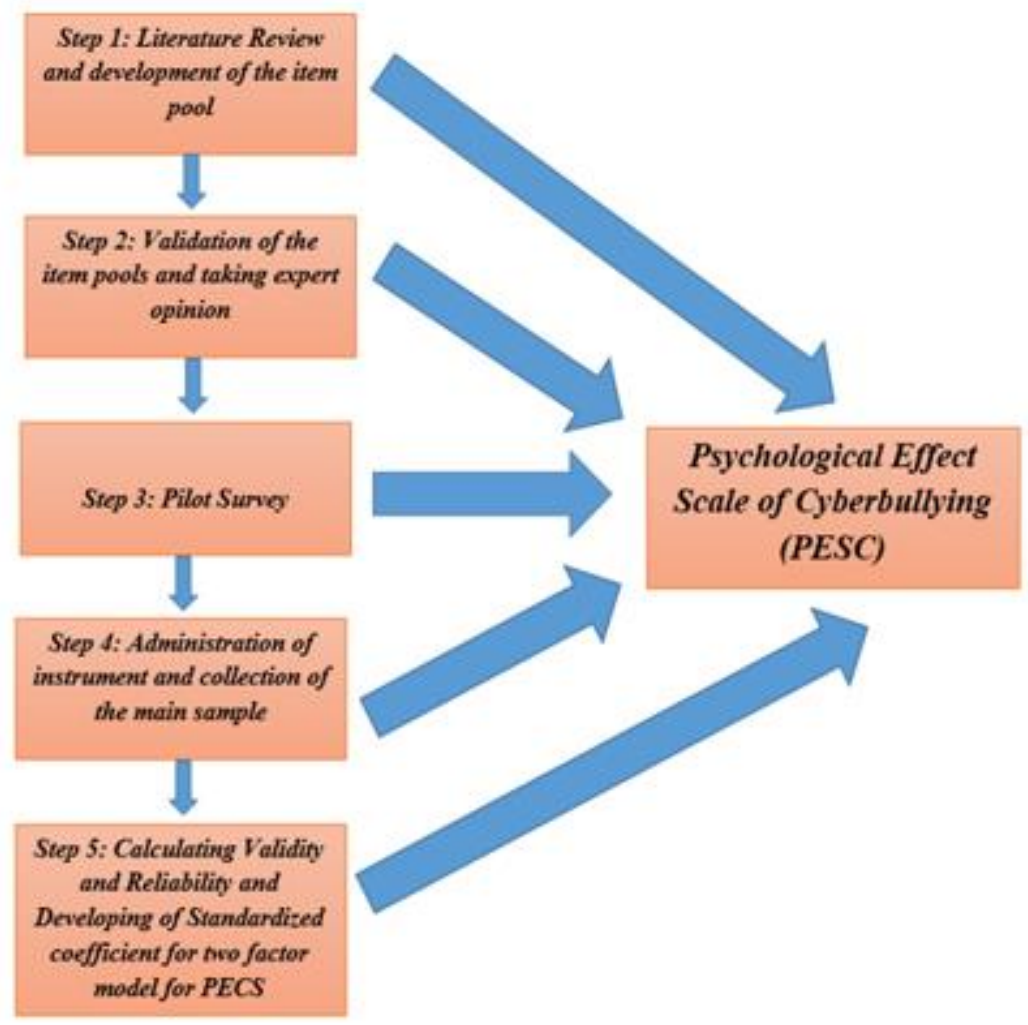

Figure 2: Development of PECS: Stepwise Development Method of Psychological Effect Scale of Cyberbullying

Source: Modified and Recreated by the Authors from the Model: https://academicjournals.org/article/article1379775527_Ugulu.pdf

\section{Step 2: Validation of the Item Pools and Taking Expert Opinion}

The researchers further evaluated the drafted list of questions. The examination was based on three areas of concern: clearness and understanding, content validity and accuracy. Each of the questions were organised in a matrix with these three concern areas. Only questions fulfilling all the three requirements were selected after revise.

The revised items were then put forward to the teachers $(n=12)$ and parents $(n=8)$. They were asked to examine the questions again with relevance to the study's purpose and objectivity. According to the suggestions received, one more question was added, and two questions were removed from the drafted list of questions, 
developed from the previously mentioned matrix.

\section{Step 3: Pilot Survey}

The initial Psychological Effect Scale of Cyberbullying (PESC) of this study was prepared according to the experts' literature survey, validity test, and opinion. It comprised of 26 direct problem-oriented questions to measure the mild and intense psychological effects of cyberbullying. Along with these problemoriented questions, some general questions related to the samples' background and overall experience of the cyberbullying were also included in the pilot survey draft questionnaire. The pilot survey was carried on 40 teenagers of minority communities, out of which 23 were females, and 17 teenagers were males. The pilot survey areas were the Muslim minoritydominated areas of Ekbalpur and Park Circus.

\section{Step 4: Administration of the Instrument and Collection of the Main Sample}

Based on the experience of the pilot survey, the final draft of the questionnaire was prepared. Two items appeared to be irrelevant and were eliminated from the item pool of PECS of the final study. All the 24 PESC related items (Appendix: A) were converted into Likert scale questions, ranging from never (1) to always (5). Close-ended questions were used mainly to study the background of the victims. It helped to minimise the occurrence of probable errors while filling in the questionnaire.

The final survey for the main study was conducted among 174 teenagers within the agegroup of 14 years to 19 years. Adolescents below 14 years were excluded from the study. The pilot survey results clearly showed that below this age, the incidence of cyberbullying is very low in the study area. Out of 174 teenagers, 95 were females, and 79 were males. The survey was conducted in the areas that have the maximum amount of Muslim minority dominance, such as Ekbalpur, Mominpur, Park Circus and Raja Bazar.

\section{Step 5: Calculating Validity and Reliability and Developing of Standardised coefficient for two factor model for PECS}

The data collected from the 174 samples were tabulated, based on the responses of PECS samples. Then an SPSS data set was developed for further analysis. The IBM SPSS Statistics 20 was used for conducting Confirmatory factor analysis (CFA). The maximum likelihood method with Varimax rotation was used for this purpose. On the basis of the CFA results, all the items of the PECS were subdivided into two groups - the Mild Psychological Effect of Cyberbullying (MPEC) and the Intense Psychological Effect of Cyberbullying (IPEC). The first group consists of 13 items of IPEC, and the later consisted of 11 items of the MPEC. They together form the 24 item pools of the PECS. To measure the consistency in the result, a Cronbach alpha test was also conducted later. The test established the reliability of the instrument of the present study.

The IBM SPSS AMOS version 20 was then used. The primary purpose was to develop a Standardised coefficient for two factor model for PECS, where the two main factor groups were MPEC and IPEC with their respective items (Appendix: B). The Standardised coefficient for the two-factor model structure was analysed. It unfolded the relation between different items to formulate a structural study of cyberbullying's psychological effects on the minority community of a cosmopolitan city like that of Kolkata.

\section{Results}

\section{Section I}

A confirmatory factor analysis (CFA) was performed to develop the structure of PECS with 24 items. To determine the structure of the scale factors, Varimax rotation method and Maximum likelihood estimates were used. The suitability of the data for factor analysis had been tested by the Kaiser-Mayer-Olkin (KMO) co-efficient and Barlett Sphericity Test. The KMO value was 0.957 (Table 1), which is highly acceptable. Bartlett's test of Sphericity is an indicator for examining the strength of the relationship between the 
variables. In the present study, the value is $p<$ .000 , which indicated a strong relationship between the variables (George \& Mallery, 2001).

\begin{tabular}{|c|c|c|}
\hline \multicolumn{2}{|c|}{ Kaiser-Meyer-Olkin Measure of Sampling Adequacy. } & 957 \\
\hline \multirow[t]{3}{*}{ Bartlett's Test of Sphericity } & Approx. Chi-Square & 9615.721 \\
\hline & Df & 276 \\
\hline & Sig. & .000 \\
\hline
\end{tabular}

Source: Computed by the Authors, 2019

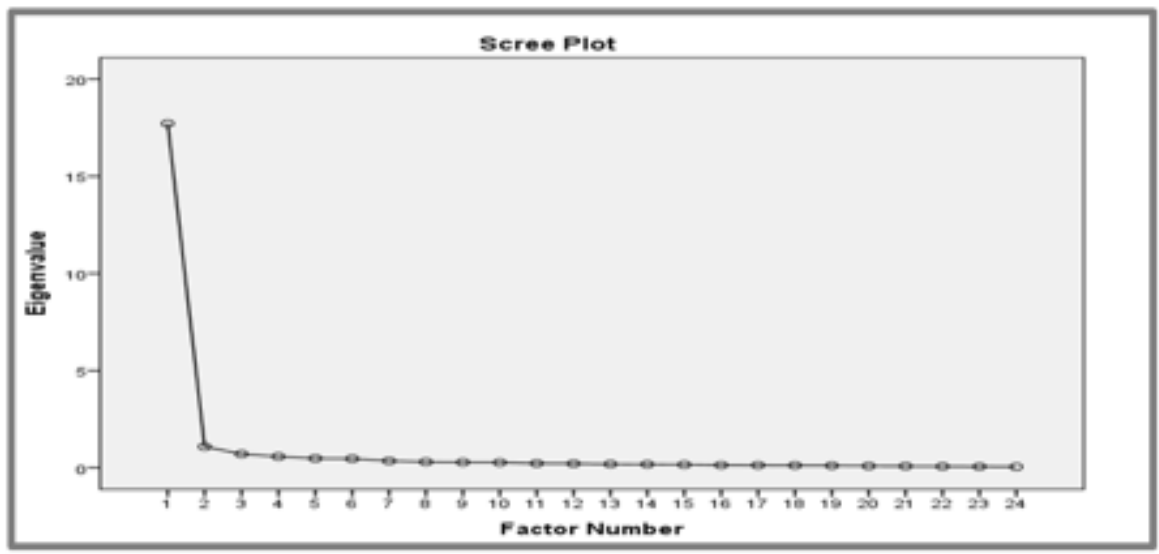

Figure 3: Scree Plot of the 24 item pools of PECS Source: Computed by the Authors, 2019

Factor Analysis of the PECS extracted two factors with Eigen values exceeding 1 . These two together explained $78.338 \%$ of the variance of results. The first factor explained $73.812 \%$ of the total variance. From the observation of the scree plot (Figure 3), it can be stated that these two factors had a larger portion of the variance. For the two factors, the descent of the line graph was sharp, and after that, it levelled off.

According to the factor analysis, the PECS items was grouped into two subgroups. The first factor comprised 11 items related to the Mild Psychological Effects of Cyberbullying (MPEC) on teenagers of the minority community. The first

\section{Section II}

factor included- cried, felt embarrassed, anxious, scared, angry, insecure, sad, temporary depression, lost temper, the problem in trusting others and started avoiding friends. The second factor included 13 items related to Intense Psychological Effects of Cyberbullying (IPEC) on teenagers of the minority community. The second factor constituted self-harm, affecting mental and physical health, long absence in school, lowering of grades in examination, feeling socially isolated, difficulty in the study, trying to ignore others, a decrease of selfesteem, blaming himself, loss of urge to go to school and thinking of committing suicide.

\begin{tabular}{|c|c|c|c|}
\hline \multicolumn{4}{|c|}{ Table 2: Reliability Statistics: Cronbach's Alpha Value of Each Factor in the PECS } \\
\hline Factor Label & Number of the items & Cronbach's Alpha & Specifications \\
\hline $\begin{array}{c}\text { Mild Psychological Effects of } \\
\text { Cyberbullying (MPEC) }\end{array}$ & 11 & 0.962 & Reflective \\
\hline $\begin{array}{c}\text { Intense Psychological Effects } \\
\text { of Cyberbullying (IPEC) }\end{array}$ & 13 & 0.979 & Reflective \\
\hline \begin{tabular}{l} 
Source: Computed by the Authors, 2019 \\
\hline
\end{tabular}
\end{tabular}


The reliability test further supported the factor analysis results. Reliability refers to the ability of the instrument used to give consistent result each time it is applied. A Cronbach alpha statistical measurement is a useful tool for measuring such reliability. A Cronbach alpha value of $\geq 0.07$ signifies a very high reliability level (Hair et al., 2010). In this study, the Cronbach alpha value extracted for both the items of MPEC and IPEC were 0.962 and 0.979, respectively (Table 2 ). Both the values were above 0.85 , which indicated a very high level of reliability. The factors were reflective in nature, as their indicators were highly correlated and displayed adequate internal consistency.

The Confirmatory Factor analysis (CFA) was conducted, using the statistical package of Analysis of Moment Structure (AMOS .20), for further confirmation and development of the standardised coefficient for two factor model for PECS (Table 3). For this study, a two-factor pattern matrix (Figure 4) have been used. The chi-square showed that the result is significant.

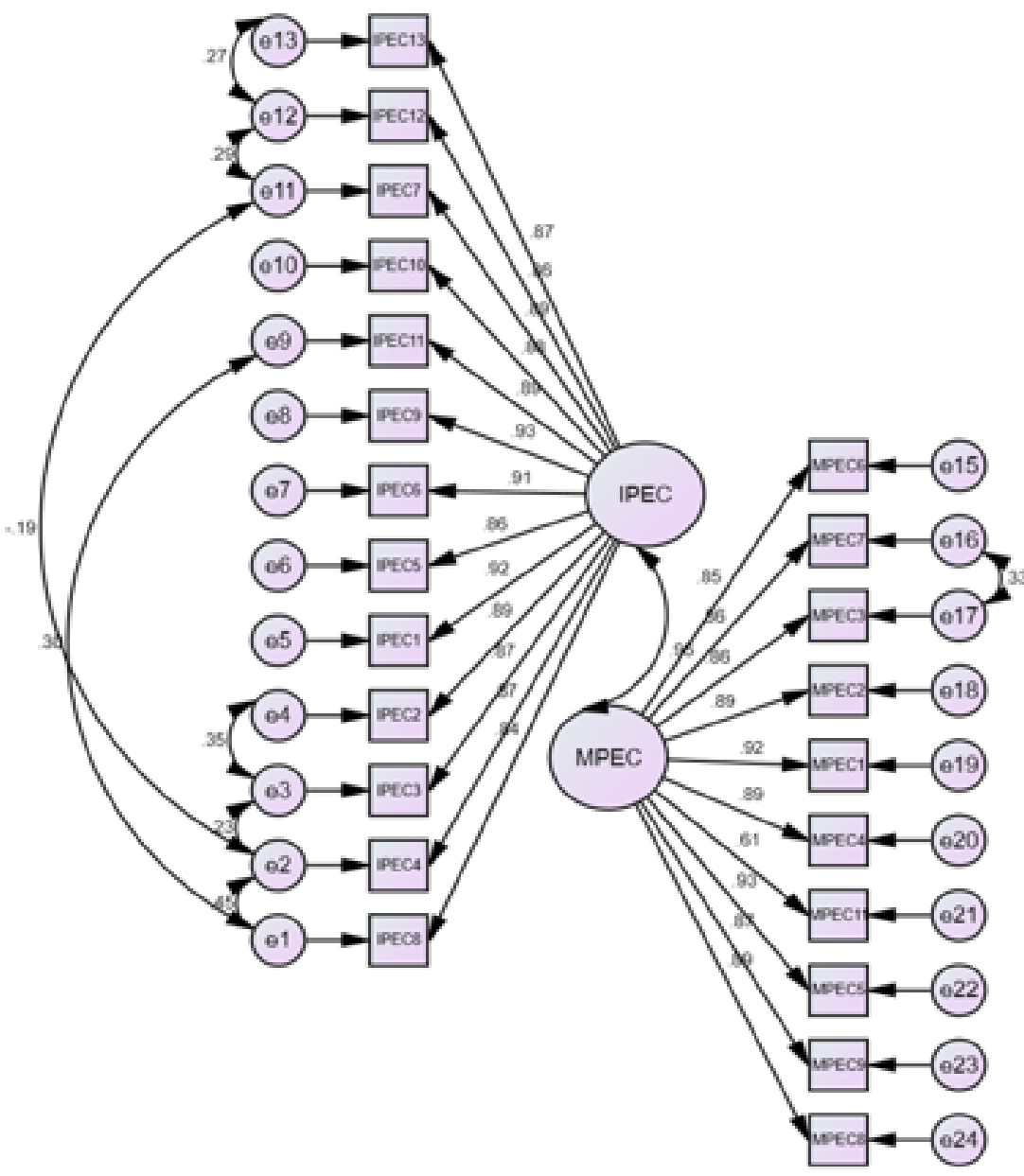

Figure 4: Standardised Coefficient for Two Factor Model for PECS: Psychological Effect of Cyberbullying Scale (PECS) comprised 24 direct item pools. The PECS was further subdivided into Mild Psychological Effect Scale (MPES) and Intense Psychological Effect Scale (IPES), which consisted of 11 and 13 item pools respectively

Source: Computed by the Authors, 2019

\section{Discussion and Implication}

\section{Section I}

The study of PECS with Confirmatory Factor Analysis (CFA) determined and evaluated the psychological impact of cyberbullying on the teenagers of the minority community. The instrument for this assessment had been developed following the five steps- 1. An extensive literature review on the environment of cosmopolitan city, socio-economic status of minority communities in Kolkata and 
psychological effects of cyberbullying on teenagers was conducted. This followed the development of initial item pools 2 . Validation of the item pools by the authors, with the help of matrix and consideration of the teachers and parents' opinion to improve the item pools 3. A pilot survey was conducted to identify the shortcomings of the drafted item pools 4 . Then we prepared the final draft of the item pools and questionnaire schedule, along with conducting the primary survey 5 . The next step followed calculating the validity and reliability of CFA. PECS consisted of the two factors of IPEC and MPEC, together consisting of 24 item pools of PECS. All these item pools were measured with the help of 5 points Likert scale ranging from never (1) to always (5). The maximum score could be 120 , and the minimum score could be 24.
The validity and the reliability of PESC were assessed using factor analysis with Varimax rotation (Table 3 ). The factor analysis results revealed two-scale structure of the instrument, that is, MPEC and IPEC. According to the surveyed literature, related to item loadings, a factor loading of 0.30 or higher is suggested for acceptance (Martin-Dunlop \& Fraser, 2007). In this study, the same principle had been followed. The cut-off score was less than and equal to 0.30 $(\leq 0.30)$. The CFA results clearly indicated significant path co-efficient $(p \leq 0.00)$ for all the items. So no items had been excluded, and each of them had a significant influence on PECS. The two main subgroups, that is, IPEC and MPEC, exerted effective influence on PECS.

Table 3: Rotated Factor Matrix: Factor Structure and Loadings of the 24 items of PECS

\begin{tabular}{|c|c|c|c|}
\hline \multirow{2}{*}{\multicolumn{2}{|c|}{$\begin{array}{c}\text { Factor } \\
\text { (Emotions and Reactions) }\end{array}$}} & \multicolumn{2}{|c|}{ Factors } \\
\hline & & \multirow{2}{*}{$\begin{array}{c}1 \\
.813\end{array}$} & \multirow[t]{2}{*}{2} \\
\hline IPEC1 & & & \\
\hline IPEC2 & & .805 & \\
\hline IPEC3 & & .794 & \\
\hline IPEC4 & & .783 & \\
\hline IPEC5 & & .768 & \\
\hline IPEC6 & & .766 & \\
\hline IPEC7 & & .724 & \\
\hline IPEC8 & & .723 & \\
\hline IPEC9 & & .715 & \\
\hline IPEC10 & & .702 & \\
\hline IPEC11 & & .702 & \\
\hline IPEC12 & & .676 & \\
\hline \multirow[t]{12}{*}{ IPEC13 } & & .637 & \\
\hline & MPEC1 & & .731 \\
\hline & MPEC2 & & .717 \\
\hline & MPEC3 & & .716 \\
\hline & MPEC4 & & .713 \\
\hline & MPEC5 & & .675 \\
\hline & MPEC6 & & .669 \\
\hline & MPEC7 & & .641 \\
\hline & MPEC8 & & .639 \\
\hline & MPEC9 & & .630 \\
\hline & MPEC10 & & .566 \\
\hline & MPEC11 & & .516 \\
\hline $\begin{array}{l}\text { Extraction Metho } \\
\text { Rotation Method: } \\
\text { Source: Computed }\end{array}$ & $\begin{array}{l}\text { ood. } \\
\text { r Normaliz }\end{array}$ & & S. \\
\hline
\end{tabular}


As stated above, the mild psychological effects included 11 items like feeling sad, angry, insecure, scared, anxious, the problem in trusting others and avoiding friends. All these mild impacts on the psychology of teenagers are short term in some instances. Certain socioeconomic and psychological factors can help a teenager to slowly and steadily heal from the trauma of being a victim. (Valkenburg \& Piotrowski, 2017). The possible socio-economic factors are the social values in general, perspectives related to cyberbullying, and the lower extent of the society's orthodoxy and radical attitude (Lee $\& \mathrm{Wu}, 2018$ ). The psychological factors like mental stability, mental health and sound maturity level of the victim, coupled with their social awareness, helped them to overcome the problem by

\section{Section II}

\begin{tabular}{|c|c|c|c|c|c|c|c|}
\hline & & & $\begin{array}{c}\text { Standardised } \\
\text { Estimates }\end{array}$ & Estimate & S.E. & C.R. & $\begin{array}{c}P \\
\text { value }\end{array}$ \\
\hline harm_others & $<---$ & IPEC & .837 & 1.000 & & & \\
\hline Suicide & $<---$ & IPEC & .871 & 1.033 & .056 & 18.372 & $* * *$ \\
\hline self_harm & $<---$ & IPEC & .873 & 1.041 & .076 & 13.739 & $* * *$ \\
\hline affect_mental_health & $<---$ & IPEC & .889 & 1.133 & .080 & 14.209 & $* * *$ \\
\hline affect_physical_health & $<---$ & IPEC & .920 & 1.161 & .077 & 15.142 & $* * *$ \\
\hline school_absence & $<---$ & IPEC & .861 & 1.145 & .085 & 13.427 & $* * *$ \\
\hline lower_grade & $<---$ & IPEC & .913 & 1.208 & .081 & 14.922 & $* * *$ \\
\hline difficult_in_study & $<---$ & IPEC & .929 & 1.206 & .078 & 15.425 & $* * *$ \\
\hline decrease_self_esteem & $<---$ & IPEC & .894 & 1.299 & .076 & 17.009 & $* * *$ \\
\hline try_ignore & $<---$ & IPEC & .879 & 1.097 & .079 & 13.917 & $* * *$ \\
\hline socially_isolated & $<---$ & IPEC & .887 & 1.072 & .076 & 14.149 & $* * *$ \\
\hline blame_myself & $<---$ & IPEC & .860 & 1.098 & .082 & 13.371 & $* * *$ \\
\hline not_feel_to_go_to_school & $<---$ & IPEC & .867 & 1.201 & .088 & 13.583 & $* * *$ \\
\hline Angry & $<---$ & MPEC & .847 & .915 & .062 & 14.699 & $* * *$ \\
\hline Insecure & $<---$ & MPEC & .855 & 1.032 & .069 & 14.984 & $* * *$ \\
\hline Anxious & $<---$ & MPEC & .858 & .914 & .061 & 15.092 & $* * *$ \\
\hline Embarrassed & $<---$ & MPEC & .889 & 1.014 & .062 & 16.404 & $* * *$ \\
\hline Cried & $<---$ & MPEC & .918 & 1.006 & .057 & 17.784 & $* * *$ \\
\hline trust_others & $<---$ & MPEC & .888 & .957 & .059 & 16.352 & $* * *$ \\
\hline temper_loss & $<---$ & MPEC & .615 & .536 & .062 & 8.574 & $* * *$ \\
\hline Scared & $<---$ & MPEC & .933 & 1.106 & .059 & 18.634 & $* * *$ \\
\hline Depression & $<---$ & MPEC & .873 & .970 & .062 & 15.718 & $* * *$ \\
\hline avoid_friends & $<---$ & MPEC & .894 & 1.000 & & & \\
\hline
\end{tabular}

themselves. Other factors that reduced the stress of the victim teens may correspond to help from the family and friends, their moral support, and parents' healthy parenting skills. However, in the absence of the factors mentioned earlier, the mild effects can be prolonged, and they can intensify the psychological impact of such bullying. So both the mild and intense psychological effects are related to each other. The intense effects ranged from affecting mental health, difficulty in concentrating in the study, long absence in school to lowering of self-esteem, blaming oneself, isolating himself from the society. It also included extreme impacts like that of harming others, self-harm, and even committing suicide (Kanwal \& Jami, 2019). 
The experience of cyberbullying is quite strenuous for the victims, and the intensity of the effects varies from person to person. It depends on the age, sex, duration of bullying experienced, socio-economic background and as well as on other factors, such as level of technology, education, cultural viewpoints of the society (Hinduja \& Patchin, 2008). Due to biological and psychological changes they are going through, the adolescents are in the most vulnerable state of mind, and they are often adversely affected by such incidents. The minority communities living in Kolkata are socially and economically backward (Skoda \& Nielsen,2014), which can intensify cyberbullying's psychological effects. The mild effects (Table 4) like that of anxiousness, embarrassment, anger and sadness often lead to crying and frequent loss of temper. The findings of this study also reveal that the victim teenagers also have a problem in trusting others, since the bully is anonymous (Kowalski \& Limber, 2007). Identity deception is often used on social media platforms to gain the trust of the victims, and afterwards, their reputation is threatened by online bullying (Wall, 2014). The findings further reveal that the participants start avoiding friends and feel insecure about their surroundings. These effects often lead to temporary depression. Some teenagers overcome these negative impacts by virtue of their moral strength, character, and attitude towards life. Sometimes they are offered help by friends, family, close relatives and teachers. However, some teenagers get engrossed with mild psychological turmoil and disturbances for a prolonged period. Soon, they become victims of intense psychological traumas and unrest. It starts affecting their concentration in study severely, and they lose interest in school. These cause long absence in school and ultimately lowering of their grades. Mental health affects physical health and low energy, nausea, vertigo and headache and pain in the body. Slowly the tendency of isolating themselves from society enhances. In extreme and worst situations, the victim may harm themselves or other peers and even think of committing suicide (Table 4).

\section{Conclusion}

The study's primary purpose was to find out the psychological effects of cyberbullying on the victim teenagers of minority communities of a cosmopolitan city using maximum likelihood estimates. All the items taken for conducting the survey were highly co-related to the psychological impact of the victim teens, and so the PECS developed for measuring the impact had significance. The study's limitation is that the data had been collected from the minoritydominated boroughs of Kolkata in the West Bengal state of India. Hence, the findings and the tool is limited to Indian scenario. The application of the tool had been done in specific circumstances and may not be generalised for all the cosmopolitan cities. The developed PECS can serve as a useful tool for the minority communities, and it can further be developed and modified for other communities as well.

\section{References}

Aftab, P. (2000). The parent's guide to protecting your child in cyberspace ( $2^{\text {nd }}$ ed.). McGraw Hill.

Aricak, T., Siyahhan, S., \& Uzunhasanoglu, A. (2008). Cyberbullying among Turkish adolescents. CyberPsychology \& Behaviour, $11(3), 253-261$.

https://doi.org/10.1089/cpb.2007.0016

Beran, T., \& Li, Q. (2005). Cyber harassment: A study of a new method for an old behaviour. Journal of Education Computing Research, 32(3), 265-277. https://doi.org/10.2190/8YQMB04H-PG4D-BLLH

Best, P., Manktelow, R., \& Taylor, B. (2014).

Online communication, social media and adolescent wellbeing: A systematic narrative review. Child and Youth Services Review, 41, 2736.

https://doi.org/10.1016/j.childyouth.2014.03.0 01

Biswas, M.Z.H. (2015). Socio Economic Conditions of Muslims of West Bengal: An Enquiry to Their Social Exclusion. International Journal of Humanities \& Social Science Studies, 2 (2), 259-266. 
http://oaji.net/articles/2015/1115-

1443862461.pdf

Boyd, N. (2000). The beast within: Why men are violent ( $1^{\text {st }}$ ed.). Greystone Book.

Brown, K., Jackson, M., \& Cassidy, W. (2006). Cyber-bullying: Developing policy to direct responses that are equitable and effective in addressing this special form of bullying. Canadian Journal of Educational Administration and Policy, 57, 1-

36. http://www.umanitoba.ca/publications/cjea p/articles/brown_jackson_cassidy.html.

Canadian Journal of Educational Administration and Policy, 57, 1-36. doi:

\subsection{6}

Bureau of Applied Statistics and Economics, Department of Statistics and Program Implementation, Government of West Bengal. District Statistical Handbook, Kolkata (2013). pp.18

Burton, S. (2014). Safegaurding children from online danger. In Burton, S., \& Reid, J (Eds)., Safegaurding and protecting children in the early years ( $1^{\text {st }}$ ed.), 131-146. Routledge.

Byrne, B.M. (2010). Structural equation modelling with AMOS basic concept, applications and programming. Taylor and Francis

Chaudhuri, S. (1990). Calcutta - The Living City, Volume II: The Present and Future, Calcutta. Oxford University Press.

Engfer, L. (2003). India in Pictures. Lerner Publishing Group.

George, D., \& Mallery, P. (2001). SPSS for Windows: Step by step. Allyn \& Bacon.

Greenfield, P.M., \& Cocking, R.R. (2014). Independence and interdependence as developmental scripts: Implications for theory, research and practice. In Greenfield, P.M. \& Cocking, R.R (Eds). Cross-culture roots of minority child development (pp. 1-41). New York: Psychology Press. https://doi.org/10.4324/9781315746555
Hair, J.R., Black, W.C., Babin, B.J., \& Anderson, R. E. (2010). Multivariate data analysis ( $7^{\text {th }} \mathrm{ed}$.). Macmillan Publishers.

High, B. (2007). Bullycide in America: Moms speak out about bullying/ suicide connection ( $1^{\text {st }}$ ed.). Washington: JBS Publishing.

Hinduja, S. \& Patchin, J.W. (2008).

Cyberbullying: An exploratory analysis of factors related to offending and victimization. Deviant Behaviour, 29 (2), 129-156.

https://doi.org/10.1080/01639620701457816

Horowitz, M., \& Bollinger, D.M. (2014).

Cyberbullying in social media within educational institutions: Featuring students, employee and parent information ( $1^{\text {st }}$ ed.). Rowman and Littlefield Publishers.

Kanwal, H.\& Jami, H. (2019). Exploring odes, strategies, and psychosocial consequences of Cyberbullying Perpetration and Victimization Among University Students. Pakistan Journal of Psychological Research, 34 (4), 787-817.DOI: 10.33824/PJPR.2019.34.4.43.

Kowalski, R.M. \& Limber, S.P. (2007). Electronic bullying among middle school students. Journal of Adolescent Health, 41(6 Suppl 1), S22-S30.

DOI: 10.1016/j.jadohealth.2007.08.017

Lee, S.S., Bashnakova, D., \& Goldblatt, J. (2017). The $21^{\text {st }}$ century meeting and event technologies: Powerful tools for better planning, marketing and evaluation ( $1^{\text {st }}$ ed.). Oakvilla, Canada: Apple Academic Press.

Lee, Y. \& Wu, W. (2018). Factors in

cyberbullying: The attitude- social influenceefficacy model. Anales de Psicologia, 34 (2), 324-331.

http://scielo.isciii.es/pdf/ap/v34n2/0212-9728ap-34-02-323.pdf

Marcum, C.D., \& Higgins, G.E., \& Ricketts, M.L. (2014). Juveniles and cyber stalking in United States: An analysis of theoretical predictors of patterns of online perpetration. International Journal of Cyber Criminology, 8 (1), 47-56. http://www.cybercrimejournal.com/marcumet alijcc2014vol8issue1.pdf

Marczak, M., \& Coyne, I. (2015). A focus on online bullying. In Attrill, $A(E d)$, 
Cyberpsychology (pp. 147-156). Oxford University Press.

Martin-Dunlop, C., \& Fraser, B.J. (2007).

Learning environment and attitudes associated with an innovative science course designed for prospective elementary teachers. International Journal of Science and Mathematics Education, 6, 163-190.

https://link.springer.com/article/10.1007/s1076 3-007-9070-2

National Crime Record Bureau, Ministry of Home Affairs, Government of India. Crime in India (2017). pp. 797

Price, M., \& Dalgleisa, J. (2010). Cyberbullying: Experience, impacts and coping strategies as described by Australian young People. Young Studies Australia, 29(2), 51-59.

http://citeseerx.ist.psu.edu/viewdoc/download ?doi=10.1.1.469.2077\&rep=rep1\&type=pdf

Shariff, S., \& Hoff, D.L. (2007). Clarifying legal boundaries for school supervision in cyber space. International Journal of Cyber Criminology, 1(1), 76-118.

http://www.cybercrimejournal.com/shaheenho ff.pdf

Singh, G., \& Kumar, M. (2014). Exploratory factor analysis of service quality dimensions for higher educational institutes: A students perspective. In Theodore. J. D. (Ed), Global Journal of Management and Business Research, 14(8), 38-48.

https://globaljournals.org/GJMBR_Volume14/6 -Exploratory-Factor-Analysis.pdf

Skoda, U., \& Nielsen, K.B. (2014). Introduction: Navigating exclusion, engineering inclusion. In Skoda, U., Nielsen, K.B., \& Fibiger, M. Q (Eds), Navigating social exclusion and inclusion in contemporary India and beyond: Structure, agents, practices (pp. 1-19). Anthem Press Usher, A. (2010). Expose your hidden talents: Behind the mask ( $1^{\text {st }}$ ed.). Xlibris Corporation. Valkenburg, P.M. \& Piotrowski, J.T. (2017). Plugged in: How media attract and affect youth. Yale University Press. https://yalebooks.yale.edu/sites/default/files/fi les/Media/9780300228090_UPDF.pdf

Wall, D.S. (2014). Policing identity crimes. In Wall, D.S., \& William, M. (Eds), Policing cybercrime: Networked and social media technologies and challenges for policing (pp. 437-460). Routledge.

DOI: $10.1080 / 10439463.2013 .780222$

Welsh Government, United Kingdom (2011). Respecting others: Cyberbullying, guidance Report of Welsh Government, Guidance Document Number: 057/2011. pp. 5-7

Ybarra, M., \& Mitchell, K. (2004). Youth engaging in online harassment: Association with caregiver-child relationships, Internet use, and personal characteristics. Journal of Adolescence. 27 (3). 319-336.

DOI: 10.1016/j.adolescence.2004.03.007 


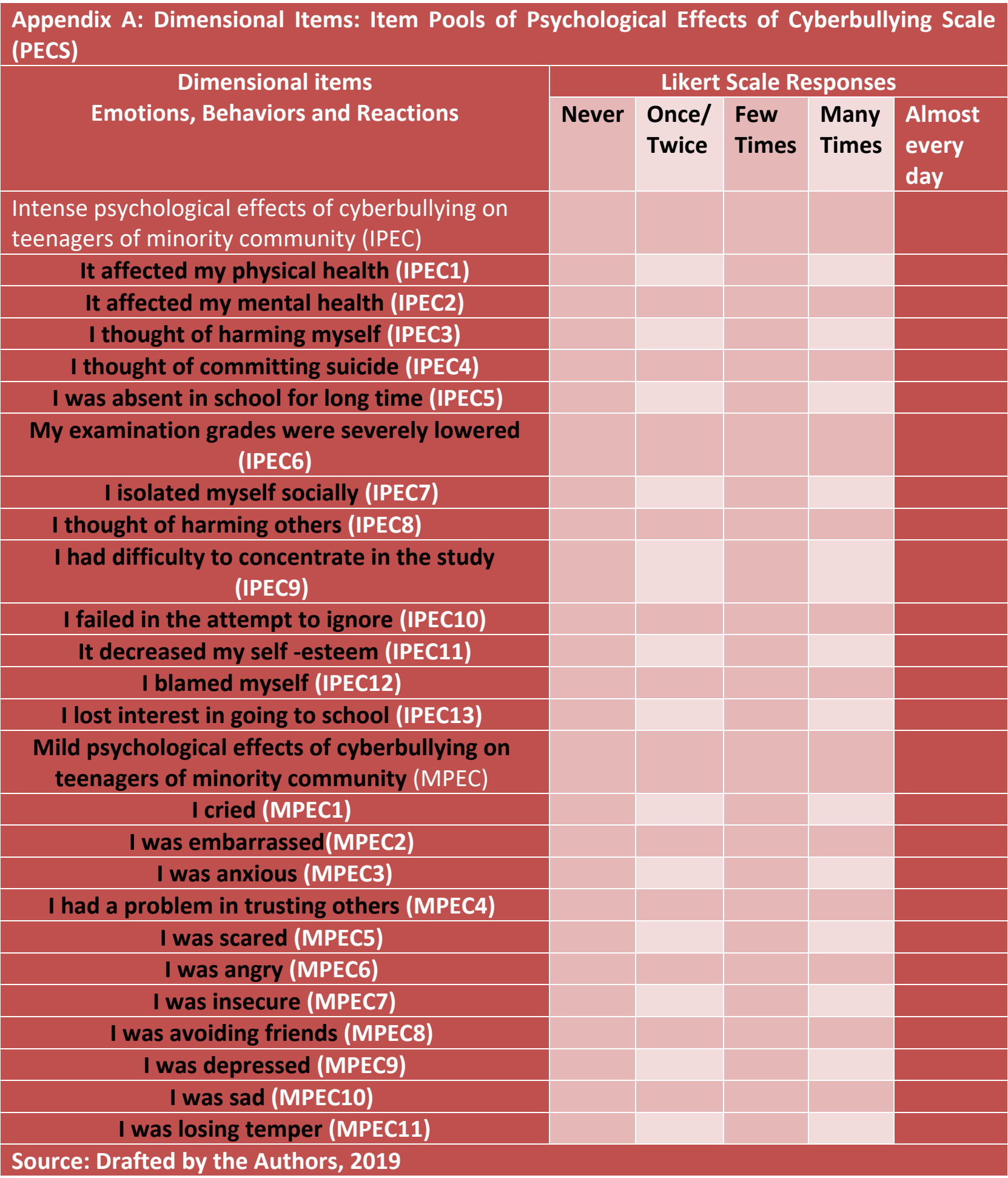




\begin{tabular}{|c|c|c|c|c|c|}
\hline \multirow{2}{*}{$\begin{array}{c}\text { Factor } \\
\text { (Emotions and Reactions) }\end{array}$} & \multicolumn{3}{|c|}{ Initial Eigenvalues } & \multicolumn{2}{|c|}{ Communalities } \\
\hline & Total & $\begin{array}{c}\% \text { of } \\
\text { Variance }\end{array}$ & $\begin{array}{c}\text { Cumulative } \\
\%\end{array}$ & Initial & Extraction \\
\hline I was sad (MPEC10) & 17.715 & 73.812 & 73.812 & .534 & .350 \\
\hline I was angry (MPEC6) & 1.086 & 4.526 & 78.338 & .797 & .729 \\
\hline I was insecure (MPEC7) & .705 & 2.939 & 81.277 & .848 & .744 \\
\hline I was anxious (MPEC3) & .575 & 2.397 & 83.674 & .814 & .754 \\
\hline I was embarrassed(MPEC2) & .478 & 1.990 & 85.664 & .865 & .803 \\
\hline I cried (MPEC1) & .464 & 1.933 & 87.597 & .852 & .840 \\
\hline $\begin{array}{l}\text { I had problem in trusting } \\
\text { others (MPEC4) }\end{array}$ & .350 & 1.458 & 89.054 & .856 & .806 \\
\hline $\begin{array}{l}\text { I lost interest in going to } \\
\text { school (IPEC13) }\end{array}$ & .300 & 1.250 & 90.304 & .863 & .751 \\
\hline I blamed myself (IPEC12) & .279 & 1.163 & 91.467 & .850 & .739 \\
\hline $\begin{array}{l}\text { I isolated myself socially } \\
\text { (IPEC7) }\end{array}$ & .266 & 1.107 & 92.575 & .855 & .774 \\
\hline I failed to ignore (IPEC10) & .223 & .927 & 93.502 & .856 & .766 \\
\hline I was losing temper (MPEC11) & .209 & .870 & 94.372 & .634 & .389 \\
\hline $\begin{array}{l}\text { It decreased my self esteem } \\
\text { (IPEC11) }\end{array}$ & .187 & .779 & 95.151 & .851 & .807 \\
\hline I was scared (MPEC5) & .175 & .729 & 95.879 & .882 & .856 \\
\hline I was depressed (MPEC9) & .157 & .652 & 96.532 & .820 & .759 \\
\hline $\begin{array}{l}\text { I was avoiding friends } \\
\text { (MPEC8) }\end{array}$ & .134 & .560 & 97.092 & .837 & .792 \\
\hline $\begin{array}{l}\text { I had difficulty to concentrate } \\
\text { in study (IPEC9) }\end{array}$ & .127 & .530 & 97.622 & .904 & .856 \\
\hline $\begin{array}{l}\text { My examination grades were } \\
\text { severely lowered (IPEC6) }\end{array}$ & .118 & .491 & 98.113 & .870 & .821 \\
\hline $\begin{array}{l}\text { I was absent in school for } \\
\text { long time (IPEC5) }\end{array}$ & .107 & .445 & 98.558 & .806 & .750 \\
\hline $\begin{array}{l}\text { It affected my physical health } \\
\text { (IPEC1) }\end{array}$ & .088 & .366 & 98.924 & .894 & .856 \\
\hline $\begin{array}{l}\text { It affected my mental health } \\
\text { (IPEC2) }\end{array}$ & .083 & .346 & 99.270 & .843 & .828 \\
\hline $\begin{array}{l}\text { I thought of harming myself } \\
\text { (IPEC3) }\end{array}$ & .068 & .283 & 99.553 & .867 & .803 \\
\hline $\begin{array}{l}\text { I thought of committing } \\
\text { suicide (IPEC4) }\end{array}$ & .059 & .248 & 99.801 & .860 & .780 \\
\hline $\begin{array}{l}\text { I thought of harming others } \\
\text { (IPEC8) }\end{array}$ & .048 & .199 & 100.000 & .844 & .731 \\
\hline
\end{tabular}

\section{Conflict of Interest}

The authors declare that they have no conflict of interest

\section{Author Contribution Statement}

Dr Shovan Ghosh has done the calculation and interpretation of section I of the article. He has 
also taken the responsibility of editing and proof Sucharita Pramanick has done the calculation checking the entire article and interpretation of section II of the article. She was engaged in data collection and data entry. 